\title{
AULAS REMOTAS EM TEMPOS DE COVID-19: A PERCEPÇÃO DE DISCENTES DE UM PROGRAMA DE MESTRADO PROFISSIONAL EM EDUCAÇÃO
}

\section{REMOTE CLASSES IN COVID-19 TIMES: THE PERCEPTION OF DISCENTS OF A PROFESSIONAL MASTER'S PROGRAM IN EDUCATION}

\section{CLASES REMOTAS EN COVID-19 TIMES: LA PERCEPCIÓN DE DISCENTES DE UN PROGRAMA PROFESIONAL DE MAESTRÍA EN EDUCACIÓN}

Ligia de Carvalho Abões Vercelli ${ }^{1}$ Vercelli.ligia@gmail.com

\section{RESUMO}

Este artigo tem por objetivo apresentar a percepção de discentes sobre aulas remotas ocorridas em um Programa de Mestrado Profissional em Educação. A pergunta orientadora do estudo foi: Quais são as percepções dos discentes de um Programa de Mestrado Profissional em Educação a respeito das aulas remotas que passaram a frequentar em função da pandemia do Covid-19? Trata-se de uma pesquisa de natureza qualitativa, e o instrumento de coleta de dados foi um questionário composto por 10 questões, além dos dados pessoais. $\mathrm{O}$ estudo teve seu foco em uma universidade privada localizada na cidade de São Paulo, sendo os sujeitos da pesquisa 12 discentes que cursam, no decorrer do primeiro semestre de 2020 , as disciplinas obrigatórias e eletivas nessa modalidade, além de seminários de pesquisa e orientações. Os resultados revelam que as aulas remotas foram muito positivas, pois mantiveram a mesma qualidade das aulas presenciais; que houve entrosamento entre professores e alunos; que ganhou-se tempo para estudar e realizar outras atividades, garantindo, assim, a continuidade dos estudos, e que economizou-se no transporte e na alimentação. Houve, enfim, um avanço para a educação, contudo, como muitos discentes responderam, não há como deixar de nos relacionar presencialmente. A proposta é que algumas atividades sejam remotas e outras presenciais.

PALAVRAS-CHAVE: AULAS REMOTAS; PROGRAMA DE MESTRADO PROFISSIONAL; COVID-19; DISCENTES. 
VERCELLI, LCA. Aulas remotas em tempos de Covid-19: a percepção de discentes de um programa de mestrado profissional em educação. Revista @ mbienteeducação. São Paulo: Universidade Cidade de São Paulo, v. 13, n. 2, p. 47-60 Mai/Ago 2020.

\section{ABSTRACT}

This article aims to present the perception of students about remote classes that took place in a Professional Master's Program in Education. The guiding question of the study was: What are the perceptions of the students of a Professional Master's Program in Education regarding the remote classes they started to attend due to the Covid-19 pandemic? It is a qualitative research, and the data collection instrument was a questionnaire composed of 10 questions, in addition to personal data. The study focused on a private university located in the city of São Paulo, and the research subjects were 12 students who took, during the first semester of 2020, mandatory and elective courses in this modality, in addition to research seminars and guidelines. The results reveal that the remote classes were very positive, as they maintained the same quality as the face-to-face classes; that there was interaction between teachers and students; that time was gained to study and carry out other activities, thus guaranteeing the continuity of studies, and that savings were made in transport and food. Finally, there was an advance for education, however, as many students responded, there is no way to stop relating in person. The proposal is that some activities are remote and others in person.

KEYWORDS: Remote Classes, Professional Master's Program. Covid-19. Students.

\section{RESUMEN}

Este artículo tiene como objetivo presentar la percepción de los estudiantes sobre las clases remotas que tuvieron lugar en un Programa de Maestría Profesional en Educación. La pregunta guía del estudio fue: ¿Cuáles son las percepciones de los estudiantes de un programa de maestría profesional en educación con respecto a las clases remotas a las que comenzaron a asistir debido a la pandemia de Covid-19? Es una investigación cualitativa, y el instrumento de recolección de datos fue un cuestionario compuesto por 10 preguntas, además de datos personales. El estudio se centró en una universidad privada ubicada en la ciudad de São Paulo, con 12 estudiantes de investigación que tomaron los cursos obligatorios y electivos en esta modalidad durante el primer semestre de 2020, además de seminarios de investigación y directrices. Los resultados revelan que las clases remotas fueron muy positivas, ya que mantuvieron la misma calidad que las clases presenciales; que hubo interacción entre profesores y alumnos; ese tiempo se ganó para estudiar y llevar a cabo otras actividades, garantizando así la continuidad de los estudios, y que se ahorraron en transporte y alimentos. Finalmente, hubo un avance para la educación, sin embargo, como muchos estudiantes respondieron, no hay forma de dejar de relacionarse en persona. La propuesta es que algunas actividades sean remotas y otras en persona.

PALABRAS CLAVE: CLASES REMOTAS; PROGRAMA DE MAESTRÍA PROFESIONAL; COVID-19; ESTUDIANTES. 
VERCELLI, LCA. Aulas remotas em tempos de Covid-19: a percepção de discentes de um programa de mestrado profissional em educação. Revista @ mbienteeducação. São Paulo: Universidade Cidade de São Paulo, v. 13, n. 2, p. 47-60 Mai/Ago 2020.

\section{INTRODUÇÃO}

A Educação Básica e a Educação Superior mundial, bem como diferentes setores da economia, estão sofrendo abruptamente em função da pandemia do Novo Coronavírus - Covid-19 -, responsável pela paralisação do mundo inteiro, desde o início do ano de 2020.

Tal situação colocou a população mundial em estado de isolamento social, ou seja, impossibilitou reuniões e atividades familiares, de trabalho, de lazer, de esporte, de estudo etc. Essa situação excepcional, não esperada pelos governantes das diversas nações, está exigindo adaptações severas, tanto físicas quanto sociais e emocionais, por parte de crianças, adultos e idosos, causando estresse, medo e preocupação, principalmente para aqueles que tiveram seus salários diminuídos ou ficaram sem renda; para aqueles que têm acima de 60 anos e pertencem ao grupo de risco, ou para aqueles que possuem alguma doença preexistente, tais como diabetes, asma, bronquite, problemas cardiovasculares ou algum tipo de câncer.

No Brasil, com o fechamento das Instituições de Ensino Superior, providências emergenciais foram tomadas pelos reitores, no caso, o uso da tecnologia, até então muito mal aceita por grande parte dos educadores, porém, solução fundamental em face desse cenário. Adotaram-se aulas remotas para que as atividades não fossem paralisadas e os estudantes prejudicados em seu processo de aprendizagem, conforme previsto na portaria $n^{\circ} 343$, publicada no dia 18 de março de 2020, no Diário Oficial da União (DOU), a qual "dispõe sobre a substituição das aulas presenciais por aulas em meios digitais enquanto durar a situação de pandemia do Novo Coronavírus - COVID-19", autorizando, em seu artigo $1^{\circ}$, aulas que utilizem as Tecnologias de Comunicação e de Informação (TIC), "[...] nos limites estabelecidos pela legislação em vigor, por instituição de educação superior integrante do sistema federal de ensino". Esse limite seria encerrado em 18 de abril, mas, infelizmente, o cenário vivido não é ainda satisfatório e, em função disso, o Ministério da Educação (MEC), por meio da portaria $\mathrm{n}^{\circ} 395$, de 15 de abril de 2020 , prorrogou o prazo por mais trinta dias, ou seja, até dia 17 de maio.

No que se refere ao Programa de Mestrado Profissional, foco deste estudo, as aulas remotas são realizadas com utilização da plataforma Hangout Meet, disponibilizada pela universidade, e ministradas pelos mesmos professores que as iniciaram presencialmente, cumprindo os horários de início e término estabelecidos no calendário escolar, enviado previamente aos discentes. Vale lembrar que não apenas as disciplinas obrigatórias e eletivas são oferecidas remotamente, mas também os seminários de pesquisa, as orientações de dissertação e, para os alunos 
que ingressaram nos anos de 2018 e de 2019, bancas de qualificação e de defesa, com a participação de familiares e amigos.

Faz-se necessário esclarecer que, embora as atividades presenciais tenham sido substituídas temporariamente por aulas remotas, o formato usado no segundo caso, de acordo com a Associação Brasileira de Mantenedoras de Ensino Superior (ABMES), é diferente da tradicional modalidade de Educação a Distância (EaD), em que o conteúdo é, na maioria das vezes, assíncrono, ou seja, sem um horário predeterminado, autoinstrucional, e conduzido por tutores. No portal do MEC, encontramos a seguinte definição para EaD.

\begin{abstract}
A Educação a Distância é a modalidade educacional na qual a mediação didático-pedagógica nos processos de ensino e aprendizagem ocorre com a utilização de meios e tecnologias de informação e comunicação, com estudantes e professores desenvolvendo atividades educativas em lugares ou tempos diversos. Esta definição está presente no Decreto 5.622, de 19.12.2005 (que revoga o Decreto 2.494/98), que regulamenta o Art. 80 da Lei $9.394 / 96$ (LDB).
\end{abstract}

As aulas remotas ocorrem de forma sincrônica, portanto com a "presença" do professor em tempo real, sendo que as dúvidas podem ser sanadas no momento em que surgem, por vídeo ou por chat.

Também é importante apontar a tomada de posição da universidade foco deste estudo diante do atual cenário. Em menos de quinze dias, o Departamento de Tecnologia ( $\mathrm{TI}$ ) adaptou todo o sistema para atender mais de 140 mil alunos, distribuídos nos diferentes cursos de graduação, de especialização lato sensu e de diversos Programas de Mestrado e de Doutorado.

Os docentes de todos esses cursos receberam um celular que, roteado à internet da instituição, acessa, pela central do professor, a sala de aula de sua disciplina, no horário já definido no início do ano letivo. Os discentes fazem o acesso de suas casas por meio de computadores, tablets e/ou celulares, pela central do aluno.

Dessa forma, a universidade garante a carga horária dos estudantes e o emprego dos professores, sem colocá-los em risco de aglomeração tanto no transporte de ida e volta quanto nas salas de aula e demais espaços.

A experiência da autora deste artigo em aula remota ocorreu também na graduação, em uma turma de $1^{\circ}$ semestre do curso de Pedagogia e em diferentes atuações no Programa de Mestrado Profissional, tais como: uma disciplina obrigatória, seminários de pesquisa, orientações, bancas de qualificação e de defesa, tanto como orientadora quanto como convidada interna e externa ao Programa. Percebendo que os discentes mantiveram, nas aulas remotas, o mesmo interesse e participação que 
tinham nas aulas presenciais do MP, surge a motivação em pesquisar a temática dando ênfase às suas vozes.

\section{BREVE PANORAMA DO REFERIDO PROGRAMA DE MESTRADO PROFISSIONAL}

Antes de apresentarmos o panorama do Programa de Mestrado Profissional da universidade, vale lembrar que essa modalidade é recente no curso stricto sensu. O primeiro Programa na área educacional, Mestrado Profissional em Gestão e Avaliação da Educação Pública, surgiu no Brasil em 1999, na Universidade Federal de Juiz de Fora (UFJF), portanto há 21 anos, e vem ganhando espaço desde então. Segundo dados da Plataforma Sucupira 2019, o Brasil conta com 50 Programas de MP, sendo 1 na Região Norte, 15 na Região Nordeste; 2 na Região Centro-Oeste; 22 na Região Sudeste e 10 na Região Sul.

Em 23 de março de 2017, a Portaria n. 389 do MEC institui, no âmbito da pós-graduação stricto sensu, a modalidade de Doutorado Profissional (DP), e até o momento contamos com dois DPs, um em Roraima e um no Paraná. Ambas as modalidades, presencial e a distância, segundo a referida portaria têm o objetivo de:

[...] capacitar profissionais qualificados para o exercício da prática profissional avançada e transformadora de procedimentos, visando atender demandas sociais, organizacionais ou profissionais e do mercado de trabalho; transferir conhecimento para a sociedade, atendendo demandas específicas e de arranjos produtivos com vistas ao desenvolvimento nacional, regional ou local; promover a articulação integrada da formação profissional com entidades demandantes de naturezas diversas, visando melhorar a eficácia e a eficiência das organizações públicas e privadas por meio da solução de problemas e geração e aplicação de processos de inovação apropriados; e, ainda, contribuir para agregar competitividade e aumentar a produtividade em empresas, organizações públicas e privadas (BRASIL, 2017, n.p.).

Os discentes que cursam o Mestrado Profissional (MP) buscam atender demandas sociais e profissionais emergentes, na maioria das vezes, de suas realidades; portanto, pesquisam a própria prática e/ou situações da escola na qual trabalham para que possam oferecer uma resposta às questões que se impõem na realidade educacional. Na nossa universidade, os/as pesquisadores/as utilizam-se da pesquisa-intervenção como metodologia. Segundo Damiani (2012, p. 3);

[...] denominam-se intervenções as interferências (mudanças, inovações) propositadamente realizadas, por professores/pesquisadores, em suas práticas pedagógicas. Tais interferências são planejadas e implementadas com base em um determinado referencial teórico e objetivam promover avanços, melhoria nessas práticas, além de pôr à prova tal referencial, contribuindo para o avanço do conhecimento sobre os processos de ensino/ aprendizagem neles envolvidos [...]. 
Gabre (2012, p. 4) ressalta que, na pesquisa-intervenção, os sujeitos podem ser "[...] tanto o pesquisador quanto os pesquisados e ambos têm um papel ativo no processo da pesquisa". Isso significa que o professor pesquisador pode intervir e propor ações sobre o contexto no qual está inserido a fim de objetivar transformação na prática pedagógica dos/as professores/as; portanto, a reflexão sobre a prática é o ponto de partida.

A autora, citando Moreira (2008) ${ }^{2}$, aponta dois princípios que regem a pesquisa-intervenção. São eles: a) a consideração das realidades sociais e cotidianas; b) o compromisso ético e político da produção de práticas inovadoras. Pautandose nesses dois princípios, Moreira (2008 apud GABRE, 2012, p. 2-3) destaca cinco características da pesquisa-intervenção, a saber:

1. Deve acontecer dentro do contexto pesquisado;

2. É desencadeada pela demanda, contribuindo na solução de problemas;

3. O pesquisador atua como mediador que articula, organiza encontros, sistematiza as vozes e os saberes produzidos pelos sujeitos envolvidos na pesquisa, agindo num processo de escuta ativa;

4. Tem de haver interação entre o pesquisador e os sujeitos da pesquisa;

5. As experiências cotidianas e práticas do coletivo, sistematizadas, permitem descobertas e elaborações teórico metodológicas.

O panorama apresentado referente ao Programa de Mestrado em Educação da nossa universidade revela que os/as pesquisadores/as buscam desenvolver pesquisas sobre situações referentes às demandas e problemas do dia a dia escolar, especialmente aqueles relacionados à gestão pedagógica, aos recursos educacionais e às práticas de ensino e aprendizagem, objetivando efetivar o diálogo entre teoria e prática, a fim de não dissociar a pesquisa das questões pedagógicas.

Desde sua aprovação, em 2011, a área de concentração na formação do Programa estruturou-se em duas linhas de pesquisa e de intervenção. Uma das linhas de pesquisa realiza suas investigações científicas sobre as concepções e ações que incidem na gestão educacional e escolar, envolvendo sistemas e unidades educacionais da escola básica, para que suas finalidades precípuas e específicas possam ser atingidas com a otimização dos meios de que dispõem.

As pesquisas desenvolvidas nessa linha têm como referência as concepções de gestão educacional, escolar e do conhecimento, abrangendo as políticas públicas em educação, o processo de avaliação institucional, o planejamento estratégico, a inovação, a formação e o trabalho dos profissionais comprometidos com a gestão participativa e democrática. Coerentemente com a área de concentração do Programa,

2 Obra referenciada por Gabre: MOREIRA, M. I. C. Pesquisa-intervenção: especificidades e aspectos da interação entre pesquisadores e sujeitos da pesquisa. In: CASTRO, L. R de; BESSET, V. L. (Org.). Pesquisa-intervenção na infância e juventude. Rio de Janeiro: NAU, 2008. 
VERCELLI, LCA. Aulas remotas em tempos de Covid-19: a percepção de discentes de um programa de mestrado profissional em educação. Revista @ mbienteeducação. São Paulo: Universidade Cidade de São Paulo, v. 13, n. 2, p. 47-60 Mai/Ago 2020.

realiza seus estudos com base na investigação das práticas dos agentes envolvidos nas atividades escolares.

A segunda linha desenvolve pesquisas a respeito de temáticas relacionadas a metodologias de aprendizagem e ensino de todos os ciclos e etapas da educação básica, focando suas investigações nas seguintes áreas do conhecimento: a) Linguagens, Códigos e suas Tecnologias; b) Ciências da Natureza, Matemática e suas Tecnologias; c) Ciências Humanas e suas Tecnologias.

Além das práticas de ensino vinculadas aos conteúdos curriculares, estuda outros fenômenos, problemas e objetos concernentes à formação e ao exercício docente e às relações da escola com o seu entorno, dentre os quais, direito à educação, cotidiano escolar, diversidade cultural, relação com a comunidade, gênero, violência, projeto pedagógico, ecopedagogia, uso educacional de tecnologias, relações étnicoraciais, inclusão e cultura de paz. Coerentemente com a área de concentração abrange demais estudos relativos às práticas dos agentes envolvidos no processo pedagógico.

Os referenciais teóricos que fundamentam as pesquisas das duas linhas estão voltados, principalmente, aos autores da Pedagogia crítica, Psicologia sóciohistórica, Teoria crítica e, principalmente, na teoria de Paulo Freire, sendo que o autor pernambucano permeia a maioria dos estudos por ser o pensador que sustenta os ideais propostos pelo Programa.

\section{METODOLOGIA}

A metodologia proposta para este estudo é de natureza qualitativa a qual, de acordo com Lüdke e André (2011), tem o ambiente natural como sua fonte direta de dados e o pesquisador como seu principal instrumento; os dados coletados são, predominantemente, descritivos; a preocupação com o processo do estudo é muito maior do que com o produto; o "significado" que as pessoas dão às coisas e à sua vida são focos de atenção especial do pesquisador e a análise dos dados tende a seguir um processo indutivo. As autoras, baseando-se em Bogdan e Biklen (1982), apontam cinco características de uma pesquisa qualitativa, a saber:

1 - A pesquisa qualitativa tem o seu ambiente natural como sua fonte direta de dados e o pesquisador como seu principal instrumento.

2 - Os dados coletados são predominantemente descritivos.

3 - A preocupação com o processo é muito maior do que com o produto.

4 - O significado que as pessoas dão às coisas e à sua vida são focos de atenção especial do pesquisador.

5 - A análise dos dados tende a seguir um processo indutivo. 
VERCELLI, LCA. Aulas remotas em tempos de Covid-19: a percepção de discentes de um programa de mestrado profissional em educação. Revista @ mbienteeducação. São Paulo: Universidade Cidade de São Paulo, v. 13, n. 2, p. 47-60 Mai/Ago 2020.

O instrumento de coleta de dados é um questionário composto por dados pessoais, tais como nome, idade, formação inicial, tempo de atuação no magistério e nível de ensino no qual leciona, seguido de 10 questões abertas apresentadas no subtítulo 4. Os participantes foram 12 alunos que cursam um Programa de Mestrado Profissional em Educação, ingressos em março de 2020, sendo 3 homens e 9 mulheres. As idades dos discentes variam de 25 a 50 anos, e o tempo de magistério de 3 a 30 anos; 8 atuam na Educação Infantil; 1 nos anos iniciais do Ensino Fundamental; 1 no Ensino Médio, 1 atua no cargo de gestão, como vice-diretor em escola que atende alunos do Ensino Fundamental II, do Ensino Médio e da Educação de Jovens e Adultos (EJA) e 1 não leciona no momento Vale mencionar que todos lecionam na escola pública.

O convite para participar da pesquisa foi feito em uma das aulas remotas e, naquele momento, houve adesão, via chat e áudio, dos 13 alunos que compunham a turma, porém um deles não devolveu o questionário respondido até a data estipulada. Houve nova solicitação, mas, mesmo assim, não obtivemos resposta. Os questionários foram enviados pela pesquisadora deste estudo, por e-mail, no dia 16 de abril de 2020 e devolvidos da mesma forma até o dia 26 de abril. Todos os estudantes assinaram o Termo de Consentimento Livre e Esclarecido, e, para assegurar o sigilo de suas identidades, os nomeamos como EMPE ${ }^{31}$, EMPE2, EMPE3, e assim por diante.

\section{A PERCEPÇÃO DE DISCENTES DE UM PROGRAMA DE MESTRADO PROFISSIOSNAL EM EDUCAÇÃO SOBRE AS AULAS REMOTAS}

Para que pudéssemos analisar as percepções dos discentes sobre as aulas remotas ministradas em um Programa de Mestrado Profissional em Educação fizemos uso de um questionário contendo 10 questões, conforme mencionado no item Metodologia. As questões foram: 1- O que você entende por aula remota?; 2 - Você havia participado de aulas remotas antes da pandemia de Coronavírus?, 3 - Você estava ou não preparado/a para ter aulas remotas? Por quê?, 4 - Quais foram as dificuldades encontradas nessa modalidade de ensino?, 5 - Quais foram as facilidades encontradas nessa modalidade de ensino?; 6 - Suas dúvidas foram respondidas pelos/as professores/as no momento da aula? Houve interação por parte dos/as professores/as? 7 - Os/As professores/as utilizaram recursos tecnológicos? Quais?; 8 - Os/As professores/as proporcionaram a participação de todos/as os/as alunos/as no decorrer das aulas?, 19 - Como foi a sua participação?, 10 - Há algo que queira acrescentar?

3 Estudantes de Mestrado Profissional em Educação 
VERCELLI, LCA. Aulas remotas em tempos de Covid-19: a percepção de discentes de um programa de mestrado profissional em educação. Revista @ mbienteeducação. São Paulo: Universidade Cidade de São Paulo, v. 13, n. 2, p. 47-60 Mai/Ago 2020.

Todos os estudantes relataram que a aula remota é aquela que ocorre a distância, por videoconferência, em tempo real, com uso de ferramentas tecnológicas, tais como slides e vídeos, que permitem a interação e a aprendizagem, com necessidade de sinal de internet e um equipamento para transmissão que pode ser computador, tablet ou smartphone.

Dos 12 discentes entrevistados, 5 relataram que nunca tiveram aulas remotas; 6 realizaram cursos na modalidade EaD, de forma assincrônica e 1 de forma híbrida, ou seja, mesclando aulas on-line e presenciais, intercalando conteúdos que se complementam.

Seis alunos disseram que não estavam preparados para terem aulas remotas, pois desconheciam as diferentes tecnologias, mas que a ajuda dos colegas foi fundamental para que aprendessem a manusear a plataforma; um deles relatou que é um ganho e um avanço para a educação. A outra metade dos discentes apontou que estava preparada para as aulas remotas e mencionou os seguintes motivos: já tinham noção de como usar as ferramentas tecnológicas, pois já haviam realizado cursos a distância; é mais fácil ser aluna do que preparar as aulas na ferramenta; de forma sincrônica há interação entre professor e aluno. Para eles, a falta de preparo estava relacionada à ausência de necessidade.

$\mathrm{O}$ momento atual fez que cada um buscasse se adequar à nova realidade para conseguir dar conta das demandas e garantir a continuidade do curso. Há a necessidade de se adaptar às novas tecnologias, dessa forma, as aulas remotas via Hangout Meet propiciaram a interação aluno/professor, obtendo respostas instantâneas, diferentemente de outros modelos a distância.

Porém, mesmo com as aulas acontecendo nos mesmos dias e horários das aulas presenciais, uma estudante aponta que a rotina de estudar em casa é diversa à da instituição, pois sempre aparece algo para desviar a atenção. Foi necessário organizar os serviços de casa, os cuidados com o filho pequeno e as saídas necessárias. Nesse sentido, Santos (2020) afirma que qualquer quarentena é sempre discriminatória, mais difícil para determinados grupos sociais do que para outros e, entre eles, o autor menciona as mulheres.

As mulheres são consideradas "as cuidadoras do mundo", dominam na prestação de cuidados dentro e fora das famílias. Dominam em profissões como enfermagem ou assistência social, que estarão na linha de frente da prestação de cuidados a doentes e idosos dentro e fora das instituições. Para garantir a quarentena dos outros, não podem observar a sua própria. São elas também que continuam a ter a seu cargo, exclusiva ou maioritariamente, o cuidado das famílias (SANTOS, 2020, s/p).

As dificuldades encontradas pelos alunos nessa modalidade de ensino foram: entender como acessar as plataformas virtuais para dar início às aulas 
VERCELLI, LCA. Aulas remotas em tempos de Covid-19: a percepção de discentes de um programa de mestrado profissional em educação. Revista @ mbienteeducação. São Paulo: Universidade Cidade de São Paulo, v. 13, n. 2, p. 47-60 Mai/Ago 2020.

remotas; localizar onde estava o link da aula ou com qual e-mail acessar (entretanto, rapidamente, essas dificuldades foram sanadas com auxílio dos professores e dos próprios colegas que deram suporte por WhatsApp); adaptar-se ao novo estilo de aula e resolver as falhas do equipamento ou internet intermitente; conseguir computador $e$ celular com memória suficiente para não travar e adequar os horários para conciliar as aulas com o aumento da demanda de trabalho virtual; administrar a perda de conexão e auxiliar as pessoas que tinham mais dificuldades com a tecnologia, pois isso tomava muito tempo, bem como a distância física das pessoas e o distanciamento no relacionamento interpessoal; dividir a atenção com outros assuntos no ambiente doméstico, por exemplo, as solicitações do filho e ligações da empresa que muitas vezes aconteciam no horário das aulas, sempre com a justificativa de ser urgente.

Vimos que as maiores dificuldades estão voltadas ao uso da tecnologia. Nesse sentido, o momento é de reflexão quanto à aprendizagem das diferentes plataformas, e quanto a tornar seu uso recorrente. De acordo com Santos (2020), a pandemia e a quarentena nos apresentam novas possibilidades de adaptação e possíveis alternativas a novos modos de vida. Assim, segundo o autor, esse momento nos faz refletir sobre diferentes modos de produzir, de consumir e de conviver. Acrescentamos à fala do autor que essa pandemia tem levado professores e alunos a avaliarem as possibilidades e facilidades oferecidas pela tecnologia, a fim de que possam repensar novas formas de ensino e de aprendizagem e quebrar barreiras e paradigmas relacionados a essa modalidade tão enraizados

Quanto às facilidades encontradas, a resposta da EMPE1 reflete a percepção de todos os discentes. Ela ressaltou que,

\begin{abstract}
Os alunos que chegam ao mestrado, normalmente já têm mais disciplina e amadurecimento suficiente para realizar as propostas de ensino na modalidade remota. A utilização de ferramentas que possibilitaram a discussão e o debate de forma síncrona atenderam às minhas expectativas, visto que houve interlocução entre os pares, foram criadas regras que proporcionaram a comunicação e o diálogo de forma clara, além da orientação e mediação dos professores durante todas as aulas [...].
\end{abstract}

Outro fator importante apontado por todos os discentes foi a otimização do tempo em função de não terem de se deslocar de casa à universidade. $O$ tempo que seria destinado ao transporte foi muito bem utilizado para complementar as leituras demandadas pelos professores das diferentes disciplinas. Além disso, ressaltaram que as aulas on-line não perderam qualidade, uma vez que, a partir da interação entre professor e aluno percebida nessas aulas, tiveram acesso ao conhecimento e puderam tirar suas dúvidas. Também tiveram a participação garantida pelos critérios didáticos adotados pelas docentes nas aulas virtuais, e o contato visual com todos da turma. 
Ao relatar os potenciais conhecimentos que decorrem de uma pandemia, Santos (2020) aponta a "elasticidade social", afirmando que o surgimento de uma pandemia exige mudanças drásticas e que estas são possíveis como "[...] ficar em casa e voltar a dedicar mais tempo à leitura e ao convívio com os filhos, consumir menos, dispensar o vício de passar o tempo nos centros comerciais [...].

Todos os discentes responderam que as dúvidas foram respondidas prontamente pelos professores por meio de chat e vídeo. Apontaram que os docentes utilizaram os recursos da plataforma, Hangout Meet, entre eles o compartilhamento de slides com os assuntos principais das aulas, de materiais como teses, dissertações e artigos para análise e arquivos próprios.

A seguir, apresentamos as respostas referentes à pergunta: Há algo que queira acrescentar? Apresentamo-las na íntegra pela riqueza nelas contida.

EMPE1 - Embora a motivação para a realização das disciplinas do mestrado em ambiente remoto tenha sido o isolamento social devido à COVID-19, acredito que a experiência foi muito positiva. Eu realmente tenho aproveitado muito as aulas, acredito que os vínculos com os professores e os colegas foi até ampliado, e por mais que pareça paradoxal, vejo que os laços foram estreitados, pois de certa forma nos aproximamos virtualmente, conhecemos até um pouquinho das particularidades de cada um, conhecemos um pedacinho da casa, vimos alguns familiares de colegas e professores, enfim, compartilhamos incertezas quanto ao período que vivemos, porém o elo de pertencimento e continuidade foi mantido, possibilitando a construção do conhecimento e as memórias do vivido.

EMPE2 - Acredito que é um avanço para a educação a utilização dessas ferramentas tecnológicas, e para quem tinha medo de substituírem a figura do professor, aqui está a resposta, pois a figura do professor é essencial para mediar todas as conversas, para desenvolver e interagir toda a aula. Parabéns aos professores, que tão rapidamente se adaptam, se organizam e se superam.

EMPE3 - A educação remota é uma grande aliada do ensino, principalmente para aqueles que não necessitam de práticas em locais específicos. Aulas de caráter mais teórico não perdem em qualidade para as aulas presenciais, se bem planejadas e organizadas. Além de evitar muitos deslocamentos para ir até a Universidade. Apesar desses aspectos, a aula presencial ainda é bastante relevante no contexto da aprendizagem.

EMPE4 - A partir dessa pandemia, talvez repensemos quais aulas, formações, reuniões devem ser realizadas presencialmente e quais podem ser realizadas a distância, visto que houve muitos ganhos em âmbito coletivo com a diminuição dos deslocamentos das pessoas, menos trânsito, menos poluição, por exemplo. Não podemos perder de vista a importância dos momentos presenciais na universidade e, no meu caso, que trabalho com educação infantil, também não podemos ter a ilusão de que a educação remota substitui tudo que nós estudamos a respeito da escola da infância $[\ldots]$.

EMPE5 - Esse modelo de aula está sendo muito útil nesse momento de pandemia, para que não haja a perda pedagógica/conhecimento/interação entre alunos e professores, porém, na minha opinião, o contato presencial não pode ser perdido, a sala de aula física não pode ser perdida, ela pode ser adaptada em novos moldes para atender a uma necessidade, mas nunca ser extinta.

EMPE7 - Poderíamos continuar tranquilamente com as aulas on-line. 
EMPE9 - Apesar de estarmos passando por momentos difíceis devido à pandemia, termos vivenciado a experiência das aulas virtuais foi muito positivo por inúmeros motivos; não ter as aulas suspensas na incerteza de quando seria o retorno pode garantir a continuidade do curso sem pensarmos em reposição ou prolongamento do curso. Contribuiu para que mantivéssemos a mente ocupada de forma produtiva num momento de confinamento. Trouxe a oportunidade de conhecer uma nova modalidade de ensino e romper com os mitos de que uma aula virtual tem menos qualidade que a presencial. E também pelo conforto, segurança e economia que essa modalidade proporciona.

EMPE11- Eu particularmente gosto desse formato de aula, por causa do tempo que ganho no percurso da escola, trabalho e casa. Fico menos cansada fisicamente e me sobra mais tempo para me dedicar aos estudos $[\ldots]$.

Os escritos revelam que as aulas remotas foram muito positivas, mantiveram a mesma qualidade das aulas presenciais, houve entrosamento entre professores e alunos, ganho de tempo para poderem estudar e realizar outras atividades, garantia da continuidade dos estudos, economia no transporte e na alimentação, um avanço para a educação e, como ressalta a EMPE1 "[...] os vínculos com os professores e os colegas foi até ampliado [...], os laços foram estreitados [...], enfim, compartilhamos incertezas quanto ao período que vivemos, porém o elo de pertencimento e continuidade foi mantido, possibilitando a construção do conhecimento e as memórias do vivido". A estudante EMPE7 reforça essa ideia, ressaltando que "poderíamos continuar tranquilamente com as aulas on-line".

\section{CONSIDERAÇÕES FINAIS}

Este artigo tem por objetivo apresentar a percepção de discentes sobre aulas remotas ocorridas em um Programa de Mestrado Profissional em Educação. Vimos quanto essas aulas foram importantes para esse grupo de estudantes e quanto eles se surpreenderam em participar dessa modalidade de ensino.

Professores e alunos tiveram de se adaptar, portanto as falhas ocorridas inicialmente quanto ao uso da plataforma fizeram parte do processo de aprendizagem de ambos os grupos. Como aponta Paulo Freire, aprendemos em comunhão e, nessa comunhão, pudemos expor nossas fragilidades e aprender com elas, pudemos contar com o apoio de discentes mais experientes em tecnologia e, acima de tudo, tivemos a certeza de que enfrentar o novo e quebrar resistências faz parte da aquisição de novos conhecimentos.

Contudo, como muitos discentes responderam, não há como deixar de nos relacionar presencialmente. A proposta é que algumas atividades sejam remotas e outras presenciais. Os dados obtidos neste estudo revelam possibilidades para 
VERCELLI, LCA. Aulas remotas em tempos de Covid-19: a percepção de discentes de um programa de mestrado profissional em educação. Revista @ mbienteeducação. São Paulo: Universidade Cidade de São Paulo, v. 13, n. 2, p. 47-60 Mai/Ago 2020.

refletirmos sobre novas ações tecnológicas no que se refere aos cursos de stricto sensu.

\section{REFERÊNCIAS}

Associação Brasileira de Mantenedoras de Ensino Superior (ABMES). Disponível em: https://abmes.org.br. Acesso em: 29 abr. 2020.

BRASIL. Educação Superior a Distância. Ministério da Educação. Disponível em: http://portal.mec.gov.br/instituicoes-credenciadas/educacao-superior-a-distancia. Acesso em: 23 abr. 2020.

BRASIL. Ministério da Educação. Institui modalidade de doutorado profissional. Disponível em: http://www.capes.gov.br/sala-de-imprensa/noticias/8328-portariainstitui-doutorado-profissional. Acesso em: 17 out. 2018.

BRASIL. Diário Oficial da União. Ministério da Educação/Gabinete do Ministro. Portaria n 343, de 17 de março de 2020. Disponível em: http://www.in.gov.br/en/web/ dou/-/portaria-n-343-de-17-de-marco-de-2020-248564376. Acesso em: 29 abr. 2020.

BRASIL. Diário Oficial da União. Ministério da Saúde/Gabinete do Ministro. Portaria $n^{\circ}$ 395, de 16 de março de 2020. Disponível em: http://www.in.gov.br/en/web/dou/-/ portaria-n-395-de-16-de-marco-de-2020. Acesso em: 29 abr. 2020.

BRASIL. Plataforma Sucupira. Disponível em https://sucupira.capes.gov.br/sucupira/ public/index.xhtml. Acesso em: 29 abr. 2020.

DAMIANI, M. F. Sobre pesquisas do tipo intervenção. In: Encontro Nacional de Didáticas e Práticas de Ensino, 16., 2012, Campinas. Anais eletrônicos... Campinas: Unicamp, 2012. Disponível em: http://infoteca.inf.br/endipe/smarty/templates/arquivos_template/ upload_arquivos/acervo/docs/2345b.pdf. Acesso em: 15 out. 2018.

GABRE, S. Contribuições da pesquisa-intervenção na construção de um projeto educativo no museu de arte: pensando a mediação cultural para a pequena infância. In: Seminário de Pesquisa em Educação da Região Sul, 9., 2012, Caxias do Sul. Anais eletrônicos... Caxias do Sul: Anped, 2012. Disponível em: http://www.ucs.br/ etc/conferencias/index.php/anpedsul/9anpedsul/paper/viewFile/2083/764. Acesso em: 15 out. 2018.

LÜDKE, M; ANDRÉ, M.E.D.A. Pesquisa em educação: abordagens qualitativas. São Paulo: EPU, 2011.

SANTOS. B.de S. A cruel pedagogia do vírus. Coimbra: Almedina, 2020. 


\section{REVISTA @imbienteeducação}

VERCELLI, LCA. Aulas remotas em tempos de Covid-19: a percepção de discentes de um programa de mestrado profissional em educação. Revista @ mbienteeducação. São Paulo: Universidade Cidade de São Paulo, v. 13, n. 2, p. 47-60 Mai/Ago 2020

\section{SOBRE A AUTORA}

LIGIA DE CARVALHO ABÕES VERCELLI. Doutora e mestre em educação pelo Programa de Pós-graduação em Educação da Universidade Nove de Julho (PPGE/Uninove). Graduada em Psicologia e em Pedagogia com especialização em Psicopedagogia. Docente do curso de Pedagogia e do Programa de Mestrado Profissional em Gestão e Práticas Educacionais (Progepe) na mesma universidade.

RECEBIDO: 03/05/2020.

APROVADO: 07/05/2020. 